\title{
Electromagnetic Characterization of a Composite (RE-CB-MT) by Time Domain Spectroscopy
}

\author{
Amina Bounar, Nacerdine Bouzit, and Nacerdine Bourouba \\ Laboratoire d'Instrumentation Scientifique (LIS), Département d'Electronique, Faculté de Technologie, \\ Université Ferhat ABBAS Sétif 1, 19000 Sétif, Algeria
}

Correspondence should be addressed to Amina Bounar; bnr.amina@hotmail.fr

Received 7 September 2016; Accepted 17 January 2017; Published 16 February 2017

Academic Editor: Jun Liu

Copyright (c) 2017 Amina Bounar et al. This is an open access article distributed under the Creative Commons Attribution License, which permits unrestricted use, distribution, and reproduction in any medium, provided the original work is properly cited.

The aim of this article is to study the dielectric behavior $(\varepsilon, \sigma)$ in microwaves domain of composites made with Epoxy Resin (RE), Carbon Black (CB), and Magnesium Titanate (MT) on a large band of frequency. This kind of composites is very solicited for applications and miniaturization of the components circuits (cavities, antennas, substrates, etc.) in hyperfrequency electronics. In this study we have also highlighted the effect of the fillers nature and their concentrations on the behavior of these composites. The results obtained by time domain spectroscopy (TDS) have revealed the strong dependence of complex permittivity of the composite materials on both the nature and the concentration of conductive environment. Low frequency analysis $(500 \mathrm{MHz})$ has been investigated to determine the conductivity of composites which is related to the percolation phenomenon. Moreover, the comparison between experimental results and theoretical models shows that the modeling Lichtenecker law is applicable to the ternary mixture in this frequency range and is in accordance with the approach postulated by Bottreau.

\section{Introduction}

The work of this paper consists of the study of the behavior of Magnesium Titanate (MT) (dielectric environment) in presence of Carbon Black (CB) (conducting environment). For this purpose we have especially determined dielectric characteristics of composites made of Resin-Epoxy (RE) loaded by Carbon Black (CB) and Magnesium Titanate (MT). In this analytic study, it has been interesting to determine the composite elements volume concentration influence on the mixture dielectric proprieties according to the dielectric parameters $(\varepsilon, \sigma)$.

This has been made possible from the exploration carried on two different mixtures or one is binary composite (RE$\mathrm{CB}$ ) and the second is ternary one distinguishing from the first by the addition of MT. This composite has an ilmenite [1] crystallographic structure which is used intentionally to see its effect on the permittivity and conductivity of the composites as well.

In order to analyze the dielectric effect produced by inclusion of one of the components in a ceramic composition of materials, we have established a study in low frequency according to loads volume fractions. The dispersion spectrum obtained from temporal signal has allowed us the ohmic performance analysis of this type of mixture and the importance of the percolation effect being present in this material.

The evaluation of the complex dielectric constant of the heterogeneous mixtures [2] has shown signs of difficulties in modeling and in experimentation. For that reason, studies have been established on the validity of the different laws of the mixture using system response-based models in an electromagnetic field. These laws are founded from the effective environment hypotheses [3] which suppose that the dielectrics properties of a heterogeneous substance could be represented by an effective dielectrics constant of a fictive material [4]. These laws remain limited by either their fields of validity according to the included loads volume fractions or their deficiency of predicting the dielectric behavior of some composites.

In our case of study, two famous mixture's laws have been taken into consideration in order to overcome some of these mentioned problems. One of these laws is Lichtenecker's modeling law being used because of its general use [5] and its adequate interpretation of the composite materials dielectric 
behavior. Besides, the law of Bottreau [6] has been of concern since it translates sufficiently the composites behavior having the percolation phenomenon.

\section{Method's Principle}

The experimental values of the complex dielectrics permittivity are obtained by the time domain spectroscopy (TDS) $[7,8]$. This technique contains two steps: The first step is assumed by the time domain reflectometry (TDR) [9] and the second is the frequency treatment of the signals and the processing data obtained from the previous step by adequate mathematic tools in order to get the desired parameters.

This experimental protocol is adapted with the study we have intended to carry on and which consists of the measurement of the dielectric specters over a wide frequency band, the composite materials providing or not conductivity. For instance, in our case of study, this experimental process has been applied for the determination of the dielectric constant $\left(\varepsilon_{s}\right)$ and the static conductivity $\left(\sigma_{s}\right)$ in the low frequency range. The basic principle uses the multiple reflections method [10]. The temporal signal being measured displays the TDR response of the dielectric material under test and from which a signal mathematical processing allows us to calculate the coefficient of reflection $\Gamma(\omega)$ by using the following expression:

$$
\Gamma(\omega)=\frac{V^{-}(\omega)}{V^{+}(\omega)},
$$

where $V^{-}(\omega)$ is the incident signal and $V^{+}(\omega)$ the reflective signal.

According to the method of adapted line, the complex permittivity is calculated from the expression:

$$
\frac{Y_{\text {in }}}{Y_{0}}=\frac{\sqrt{\varepsilon^{*}} \tanh (s)+1}{1+j(\omega d / c)(\tanh (s) / s)} .
$$

$\left(Y_{\text {in }}\right)$ is the input admittance, $\left(Y_{0}\right)$ is the characteristic admittance, and $s$ is given by the following expression:

$$
s=j \frac{\omega d}{c} \sqrt{\varepsilon^{*}} .
$$

$(\omega)$ is the signal frequency, $(d)$ is the sample thickness, and $(c)$ is the light speed in the vacuum according to Debye model [4]. The dielectric permittivity in low frequency is given by the expression:

$$
\varepsilon^{*}(\omega)=\varepsilon_{\infty}+\frac{\varepsilon_{s}-\varepsilon_{\infty}}{1-j \omega \tau}-j \frac{\sigma_{s}}{\omega \varepsilon_{0}} .
$$

The third term intervenes as the static conductivity parameter $\left(\sigma_{s}\right)$ which we substitute with another parameter expressed by

$$
\varepsilon_{\mathrm{s}}^{\prime \prime}=\frac{\sigma_{\mathrm{s}}}{\omega \varepsilon_{0}}
$$

$\left(\varepsilon_{s}^{\prime \prime}\right)$ characterize the ohmic contribution of the composite in low frequency spectrum.

\section{Preparation of Samples}

The composite materials to characterize are random mixtures made of Epoxy Resin (RE) used like matrix that we fill with two components: the Carbon Black (CB) which is a thin black powder with spherical particles and the Magnesium Titanate (MT) in white powder with $99 \%$ of purity. The samples are prepared at room temperature and under an atmospheric pressure with the load constituents partitioned in volume fraction from $0 \%$ to $30 \%$ with step of $5 \%$. The RE matrix is fixed at $70 \%$ in order to have a better mixture viscosity [11]. The characterization is performed from a measurement bench with a coaxial line, in which the samples have to be well-adapted so that the composite sample with two parallel faces should have a toroid form with $7 \mathrm{~mm}$ outer diameter, $3 \mathrm{~mm}$ inner diameter, and $1,9 \mathrm{~mm}$ to $2 \mathrm{~mm}$ thickness.

\section{Theoretical Model}

A descriptive study of heterogenic mixtures dielectric behavior has been made by several classical mixtures laws [1113]. One of these being used in our paper work is the Lichtenecker law [5] which seems to be a very general use because it translates satisfactorily the dielectric behavior of the composite materials. Additionally, Bottreau's law [6] has been intervened since it gives a better explanation of the composites behavior that exhibit the percolation phenomenon.

4.1. Lichtenecker Mixture Law. This law [5] is adopted for predicting the binary or ternary heterogeneous behavior and for the calculation of mixtures permittivity. For binaries composites the equation is written as follows:

$$
\ln \left(\varepsilon_{s}\right)_{\mathrm{ef}}=V_{1} \ln \varepsilon_{1}+V_{2} \ln \varepsilon_{2}, \quad V_{1}+V_{2}=1,
$$

where $V_{1}$ and $V_{2}$ are, respectively, the volumes fractions of both matrix and the loads with their respective permittivity $\left(\varepsilon_{1}\right),\left(\varepsilon_{2}\right)$.

Figure 1 present the modeling of dielectric behavior of composites with the Lichtenecker law for the binary composite of Carbon Black (RE-CB); the study concerns the evolution of the real part of the permittivity $\left(\varepsilon^{\prime}\right)$ in concentration terms.

It is noted that the model of Lichtenecker does not follow the experimental curve and more precisely in average concentrations of the Carbon Black (between 10 to 20\% of $\mathrm{CB})$.

For ternary composites, the law is presented under the following form:

$$
\begin{aligned}
\ln \left(\varepsilon_{s}\right)_{\mathrm{ef}}=V_{1} \ln \varepsilon_{1}+V_{2} \ln \varepsilon_{2}+V_{3} \ln \varepsilon_{3}, & \\
& V_{1}+V_{2}+V_{3}=1 .
\end{aligned}
$$

Figure 2 presents the modeling of dielectric behavior of composites with the Lichtenecker law for ternary composites (RE-CB-MT); the study concerns also the evolution of the real part of the permittivity $\left(\varepsilon^{\prime}\right)$.

According to the experimental results and the Lichtenecker model, it is noticeable that, on the contrary to the 


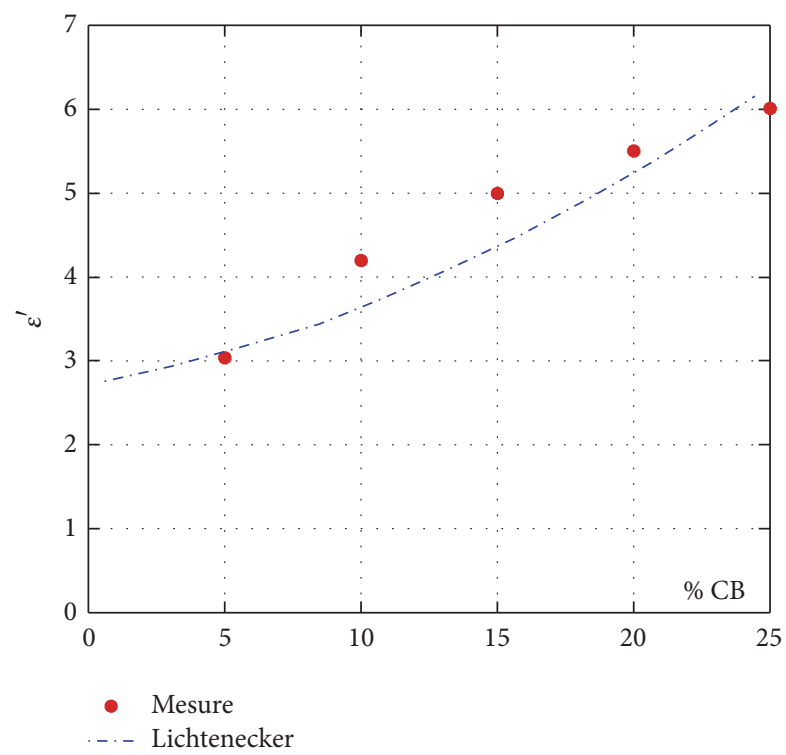

FIGURE 1: Evolution of the permittivity $\left(\varepsilon^{\prime}\right)$ for binary composites (RE-CB) (comparison with the Lichtenecker model).

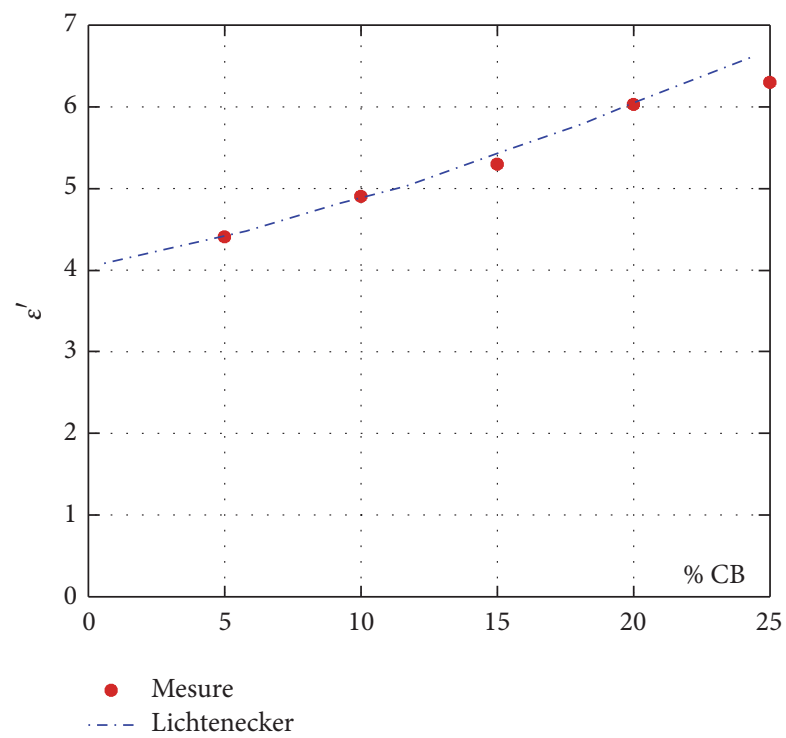

FIGURE 2: Evolution of the permittivity $\left(\varepsilon^{\prime}\right)$ for ternary composites (RE-CB-MT) (comparison with the Lichtenecker model).

binary composite, both experimental and theoretical curves of $\left(\varepsilon^{\prime}\right)$ agreed perfectly to each other up to $20 \%$ of the CB concentration.

4.2. Bottreau Mixture Law. Some dielectrics composites that have percolation phenomenon do not respond to Lichtenecker law. For this reason, Bottreau [6] made a graphic representation of the permittivity logarithm not according to the load volume fraction, but to his logarithm. For the binary composites the equation is written as follows:

$$
\ln (\varepsilon)=P_{1} \ln \varepsilon_{1}+P_{2} \ln \varepsilon_{2} .
$$

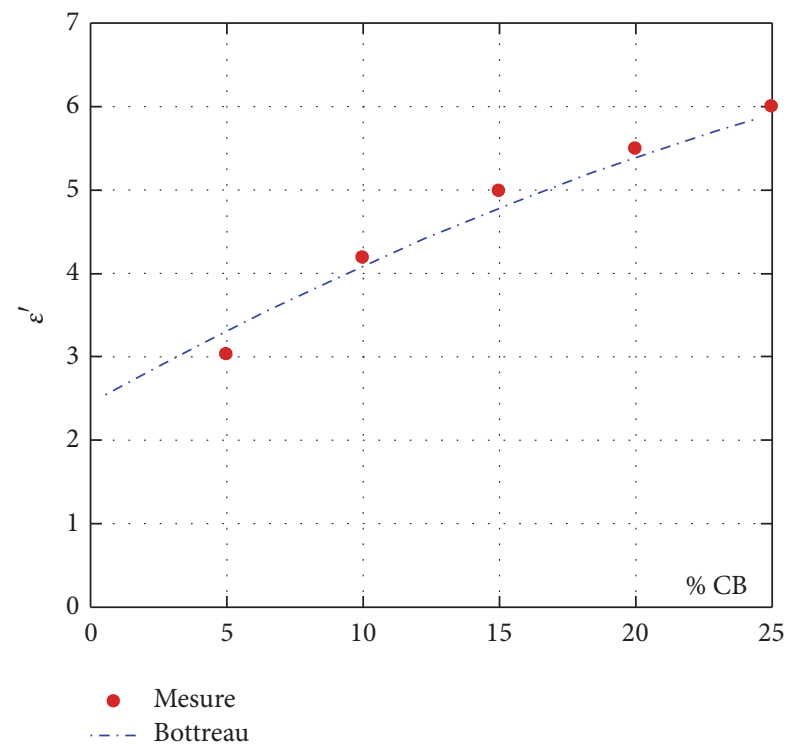

FIGURE 3: Evolution of the permittivity $\left(\varepsilon^{\prime}\right)$ for binary composites (RE-CB) (comparison with the Bottreau model).

$P_{1}$ and $P_{2}$ are the probabilities of constituents, given by

$$
\begin{aligned}
& P_{1}=\frac{\left(\left(V_{1}\right) /\left(1-V_{i}\right)\right)^{\alpha}}{\left[\left(V_{2} / V_{i}\right)^{\alpha}+\left(V_{1} /\left(1-V_{i}\right)\right)^{\alpha}\right]}=\frac{1}{1+V_{N}^{\alpha}}, \\
& P_{2}=\frac{\left(V_{2} / V_{i}\right)^{\alpha}}{\left[\left(V_{2} / V_{i}\right)^{\alpha}+\left(V_{1} /\left(1-V_{i}\right)\right)^{\alpha}\right]}=\frac{1+V_{N}^{\alpha}}{V_{N}^{\alpha}} ;
\end{aligned}
$$

$V_{i}$ is the volume fraction of the load at the inflection point and $\alpha$ is the Bottreau parameter of distribution.

Figure 3 shows the Bottreau law modeling of the composites dielectric behavior for a binary composite (RE-CB) whose graphic study concerns the real part of the permittivity.

The (RE-CB) behavior presents a total concordance between the Bottreau theoretical model and experimental results. In view of these results, these curves translate well the behavior of real part of the permittivity according to the load volume fraction. The deduced parameter of distribution for binary composites (RE-CB) is $\alpha=0.98$ at $V_{i}=0.15$.

For the ternary composites the equation is written in this way:

$$
\ln (\varepsilon)=P_{1} \ln \varepsilon_{1}+P_{2} \ln \varepsilon_{2}+P_{3} \ln \varepsilon_{3} .
$$

The real part of the permittivity graph of Figure 4 illustrates the modeling Bottreau law of the ternary composites (RE-CBMT) dielectric behavior.

The parameter of distribution for ternary composites (RE-CB-MT) is about $\alpha=0.96$, at $V_{i}=0.15$. The dielectric response depends on several parameters such as the permittivity of the constituents, the grains forms, and the spatial division of the inclusions. The results are perfectly concordant if compared to the approached value and they show at least that the best agreement is obtained using Bottreau's law for both types of mixture. However, the Lichtenecker mixture law 


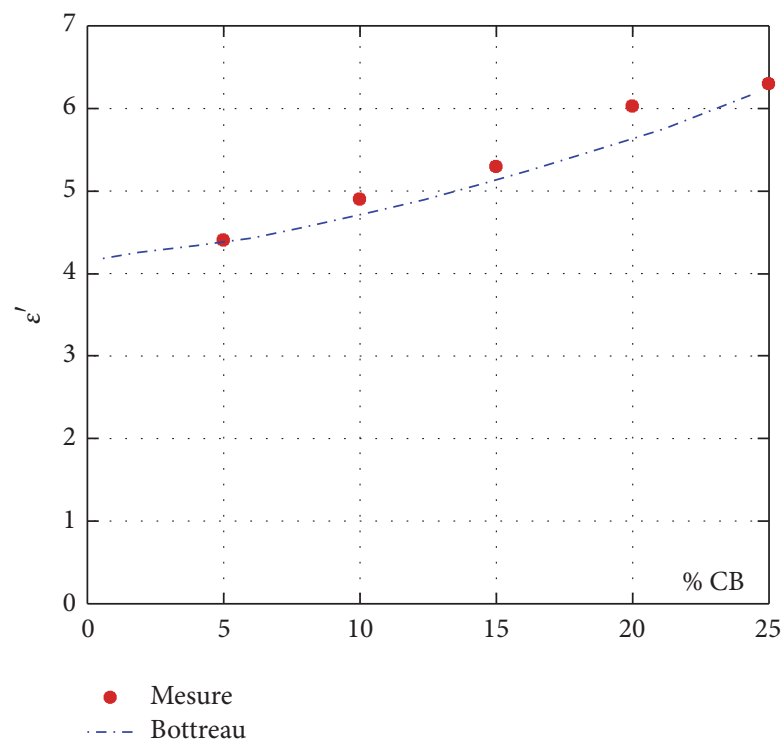

FIGURE 4: Evolution of the permittivity $\left(\varepsilon^{\prime}\right)$ for ternary composites (RE-CB-MT) (comparison with the Bottreau model).

does fit better the ternary composites (RE-CB-MT) behavior than the binary composites (RE-CB) one.

4.3. Calculation of the Shape Factor. According to the law of Lichtenecker [5] given by the following general expression:

$$
\ln \left(\varepsilon_{\mathrm{ef}}\right)=\sum_{k} V_{k} \cdot \ln \left(\varepsilon_{k}\right),
$$

the shape factor is a mean introduced in the mixture law in order to allow the agreement between the experimental and the theoretical values where it is integrated automatically in volume fraction in the Lichtenecker law. In our study's case, the shape factors $B_{L}$ and $A_{L}$ as expressed in (12) and (13) are for binary (RE-CB) and ternary (RE-CB-MT) composites, respectively:

$$
\begin{aligned}
& \varepsilon_{\mathrm{ef}}=B_{L} \cdot \varepsilon_{\mathrm{C} 1}^{x} \cdot \varepsilon_{\mathrm{C} 2}^{y} . \\
& \varepsilon_{\mathrm{ef}}=A_{L} \cdot \varepsilon_{\mathrm{C} 1}^{x} \cdot \varepsilon_{\mathrm{C} 2}^{y} \cdot \varepsilon_{\mathrm{C} 3}^{z} .
\end{aligned}
$$

$(\varepsilon)_{\mathrm{ef}}$ is the effective permittivity of the mixture and $\varepsilon_{\mathrm{C} 1}^{x}$ and $\varepsilon_{\mathrm{C} 2}^{y}, \varepsilon_{\mathrm{C} 3}^{z}$ represent, respectively, the dielectric constant of constituents $C 1, C 2$, and C3. $x, y$, and $z$, are the volumes fractions of constituents.

Figures 5 and 6 show the evolution of the shape factor according to volume fraction of $\mathrm{CB}$ for the two composites (RE-CB) and (RE-CB-MT).

The shape factor of this mixture $B_{L}$ varies around the unity and thus confirms the validity of the Lichtenecker modified law. On this regard for the mixture (RE-CB), we noted a minimum value $B_{L}=0.96$ for the charge fraction value of $25 \%$ of $\mathrm{CB}$ and a maximum value $B_{L}=1.015$ for $10 \%$ of CB. In the same way, the ternary composite (RE-CB-MT) has led to the minimum value of $A_{L}$ equal to 0.91 for the load rate of $25 \%$ of $\mathrm{CB}$ and its maximal value is about 0.97 for $20 \%$ of CB load.

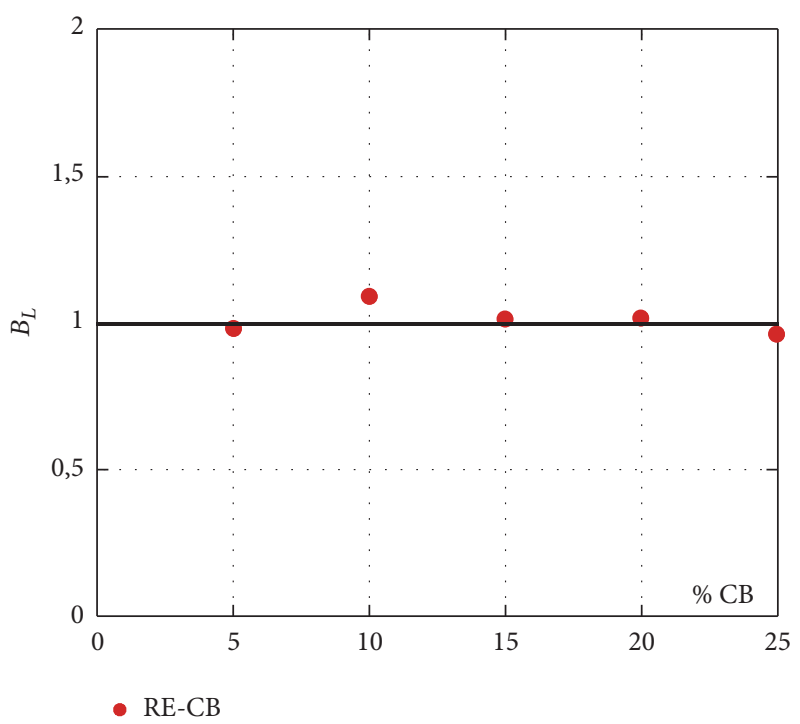

FIGURE 5: Variation of the shape factor $\left(B_{L}\right)$ for binary (RE-CB) composite.

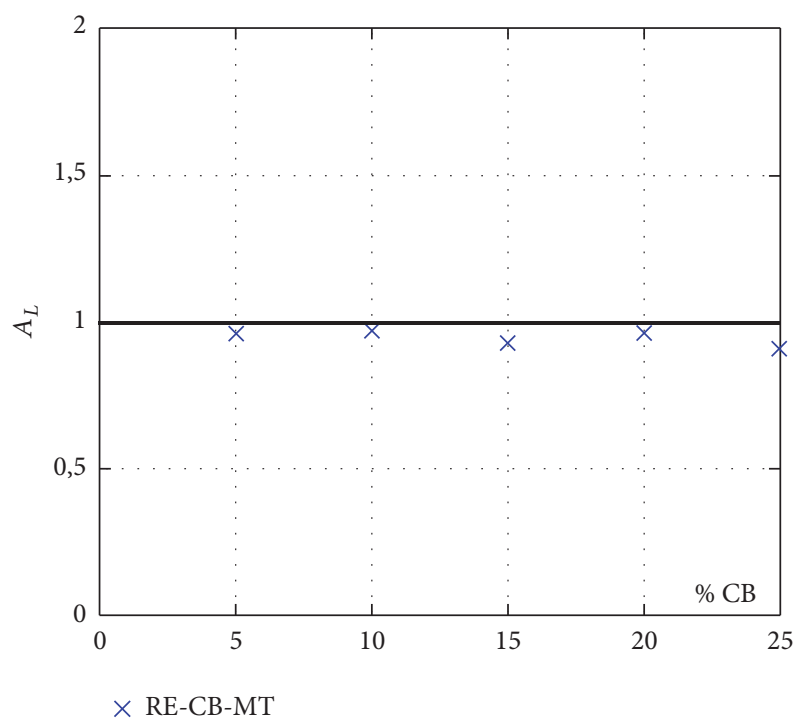

FIgURE 6: Variation of the shape factor $\left(A_{L}\right)$ for ternary (RE-CBMT) composite.

\section{Spectral Analysis}

Figures 7 and 8 indicate, respectively, the variation of the permittivity according to the frequency [DC-10 GHz] of binary composites (RE-CB) and ternary composites (RE-CBMT).

In Figure 7 the curves of $\left(\varepsilon^{\prime}\right)$ show us an increase in the real permittivity, though regular but low for high load of CB. In spite of the presence of week fluctuations that are generally due to hazardous errors of measurements, the spectrums are relatively flats with an almost constant level which tend to reducing lightly while approaching high frequency values.

According to Figure 8, the curves family of the dielectric permittivity $\left(\varepsilon^{\prime}\right)$ showed a constant dielectric value along the frequency spectrum. A significant inflection of this 


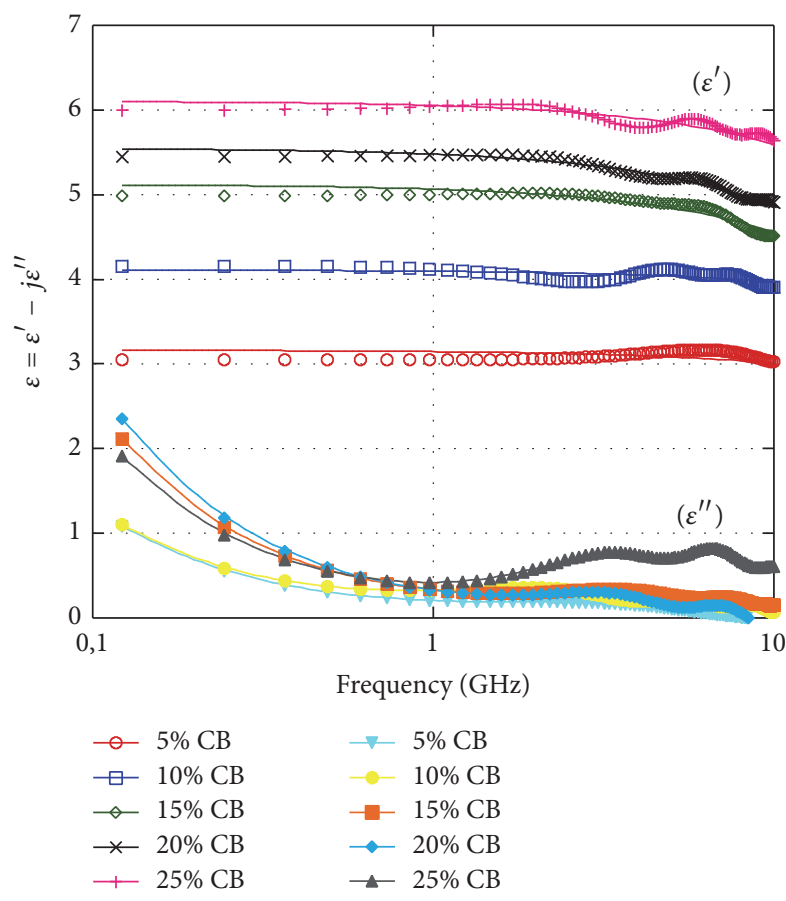

FIGURE 7: Variation of permittivity $(\varepsilon)$ for binary composites (RE$\mathrm{CB})$ as a function of frequency.

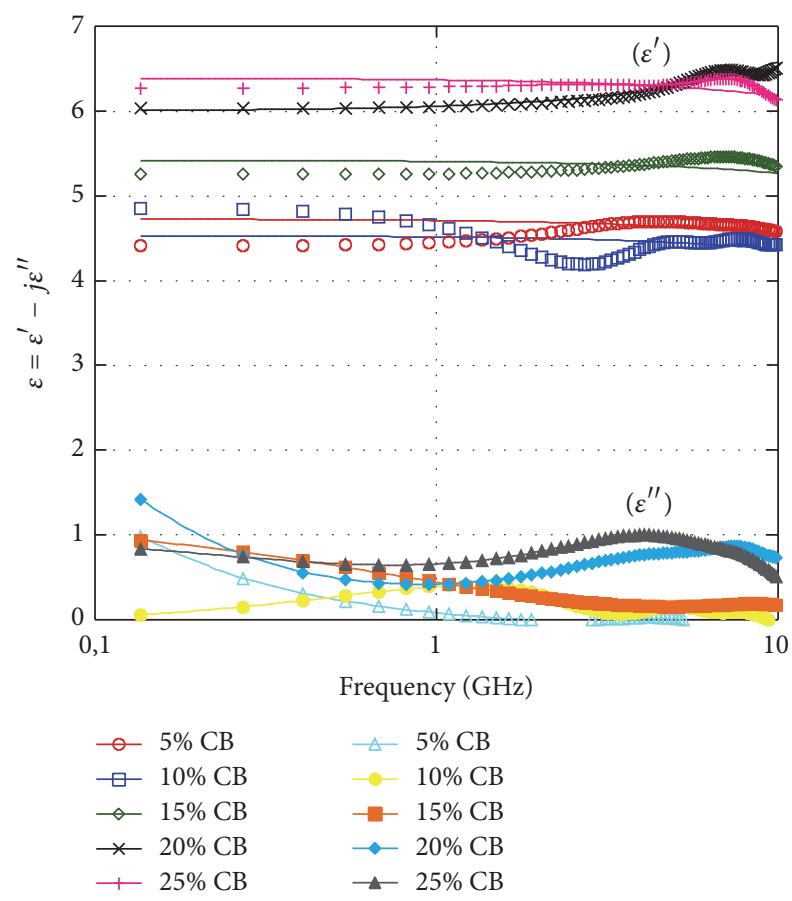

FIGURE 8: Variation of permittivity $(\varepsilon)$ for ternary composites (RECB-MT) as a function of frequency.

spectrum rather appears at (70-10-20) composition of (RECB-MT) composite which could be explained by a relaxation phenomenon. In addition, another outstanding effect characterized by the dielectric losses growth arises at the same composition which is due to the substantial Carbon Black addition that acts on the conductivity of the composite.

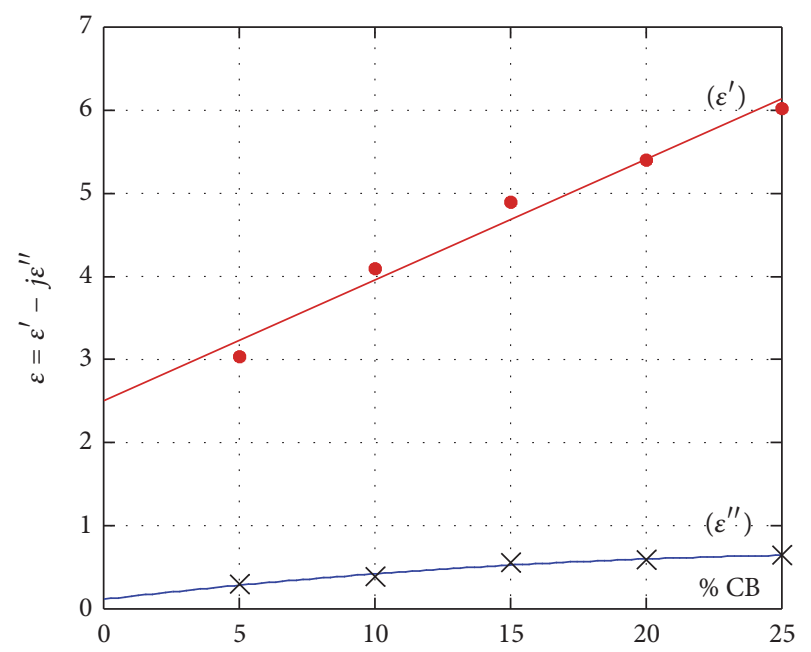

FIgURE 9: Evaluation of the static permittivity $\left(\varepsilon_{s}\right)$ for binary composites (RE-CB).

\section{Low Frequency Analysis}

The dielectric behavior analysis in low frequency is located in frequency region varying from DC till $500 \mathrm{MHz}$ for both the binary (RE-CB) and the ternary (RE-CB-MT) composites cases.

6.1. Binary Mixture (RE-CB) Case. The variations of the permittivity according to the volume concentration of inclusions are given in Figure 9.

The permittivity real term shows a consequent linear augmentation when CB rate is increasing. However the imaginary part of the permittivity varies weakly which constitutes the study of concern of the conduction phenomenon in the mixtures.

6.1.1. The Conductivity Study. Figure 10 illustrates the permittivity variation $\left(\varepsilon_{s}\right)$ as well as the static conductivity $\left(\sigma_{s}\right)$ for binary (RE-CB) mixture. We can appreciate the augmentation of these two parameters with the increasing of the concentration of $\mathrm{CB}$; this is due to a strong contribution of static conductivity in the imaginary part of the dielectric constant calculated from the following expression $[14,15]$ :

$$
\sigma_{s}=\varepsilon_{L F}^{\prime \prime} \varepsilon_{0} \omega=2 \pi f \varepsilon_{L F}^{\prime \prime} \varepsilon_{0},
$$

where $\varepsilon_{L F}^{\prime \prime}$ is the ohmic contribution to dielectric permittivity and $\sigma_{s}$ is the static conductivity at low frequencies.

From Figure 10, the maximal value of $\left(\sigma_{s}\right)$ is $18.08 *$ $10^{-3}(\Omega \mathrm{m})^{-1}$ obtained for a concentration of $25 \% \mathrm{CB}$; however the minimal value of $\left(\sigma_{s}\right)$ is $8.34 * 10^{-3}(\Omega \mathrm{m})^{-1}$ with CB concentration of $5 \%$. Between these two proportions we can note a slight but linear augmentation of $\left(\sigma_{s}\right)$ values according to $\mathrm{CB}$ volume fractions.

6.2. Ternary Mixture (RE-CB-MT). Figure 11 represents the evolution of the permittivity according of the $\mathrm{CB}$ volume fractions of the ternary composites (RE-CB-MT). 


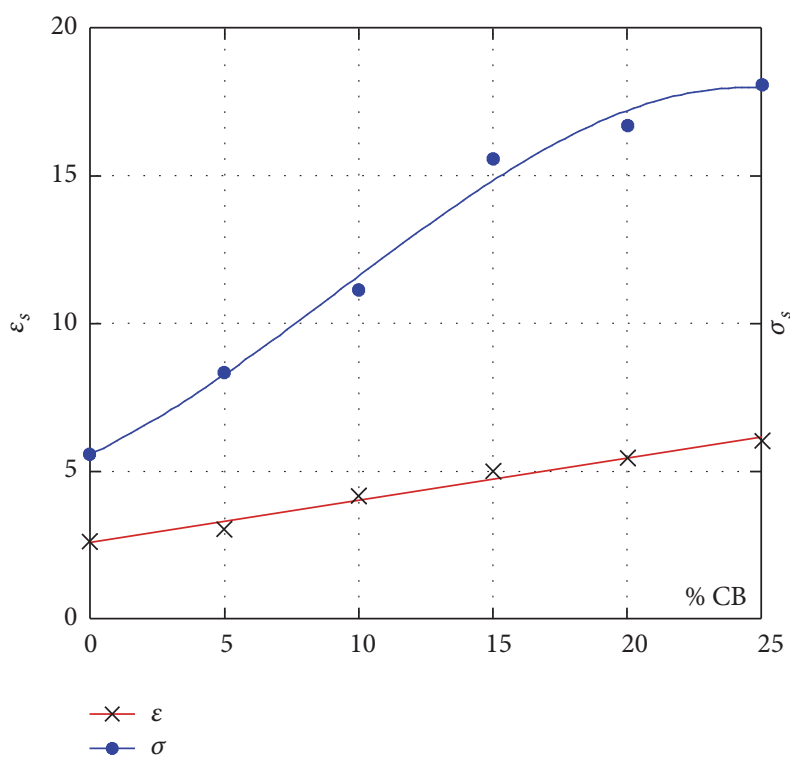

FIgURE 10: Variation of the static conductivity $\left(\sigma_{s}\right)$ and the static permittivity $\left(\varepsilon_{s}\right)$ for binary composite (RE-CB) $\left[\sigma_{s} * 10^{-3}(\Omega \mathrm{m})^{-1}\right]$.

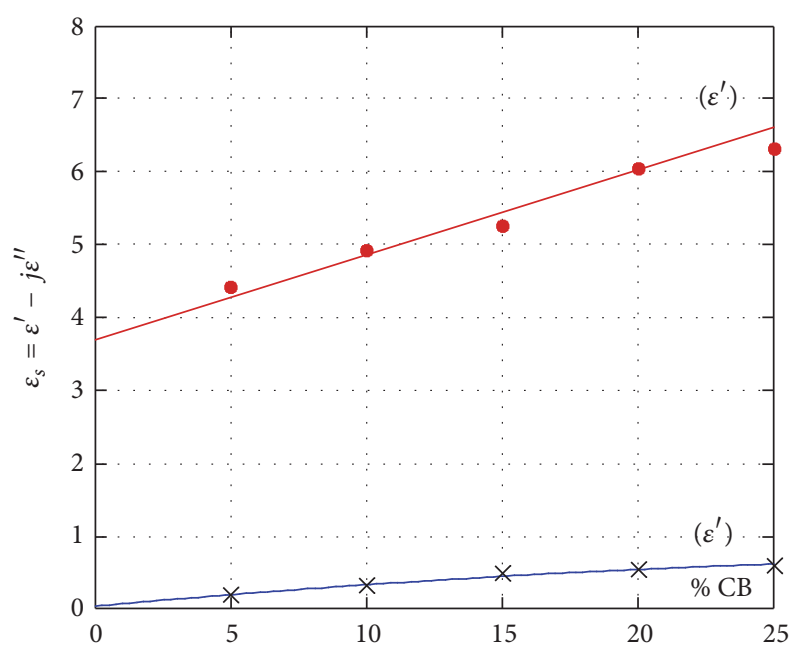

FIGURE 11: Evaluation of the static permittivity $\left(\varepsilon_{s}\right)$ for ternary composites (RE-CB-MT).

One can notice that the evolution of permittivity $\left(\varepsilon_{s}\right)$ of our samples according to the volume concentration of $\mathrm{CB}$ is in quasi-linear progression. We observed a regular weak augmentation of $\left(\varepsilon^{\prime}\right)$ according to charge rates of CB as well. Nevertheless, the variations of the permittivity imaginary term $\varepsilon^{\prime \prime}$ remain too weak, and the corresponding curve exhibits a change in concavity which translates the phenomenon of percolation.

6.2.1. The Conductivity Study. Figure 12 gives an illustration of the evolution of both the static dielectric constant and the static conductivity of the composite; the calculation of the latter is done from (14).

Beyond a CB volume concentration of $10 \%$ a change in the concavity appears with a remarkable static conductivity values augmentation. This is due to the presence of $\mathrm{CB}$

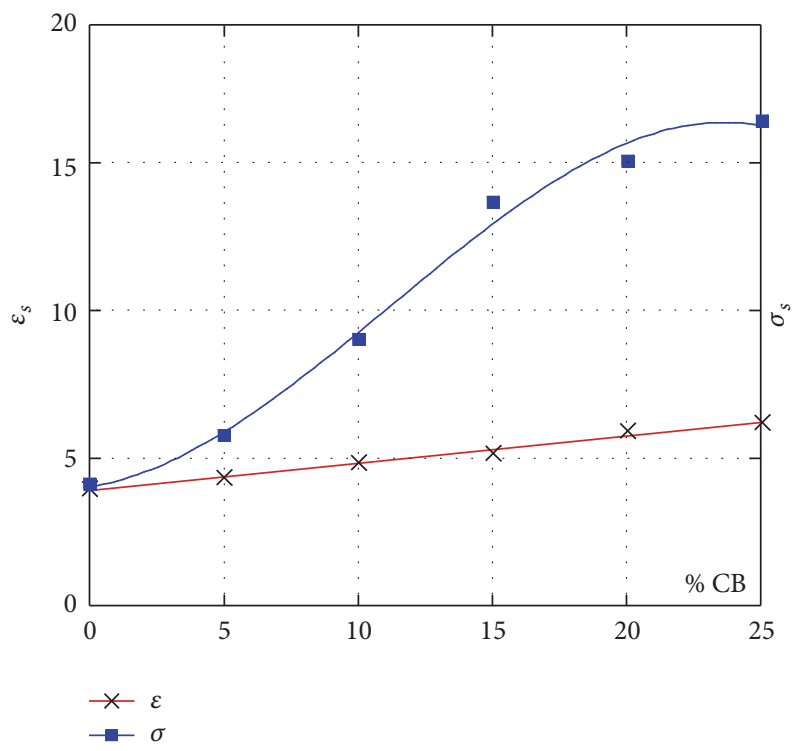

FIGURE 12: Variation of the static conductivity $\left(\sigma_{s}\right)$ and the static permittivity $\left(\varepsilon_{s}\right)$ for ternary composite (RE-CB-MT) $\left[\sigma_{s} * 10^{-3}(\Omega \mathrm{m})^{-1}\right]$.

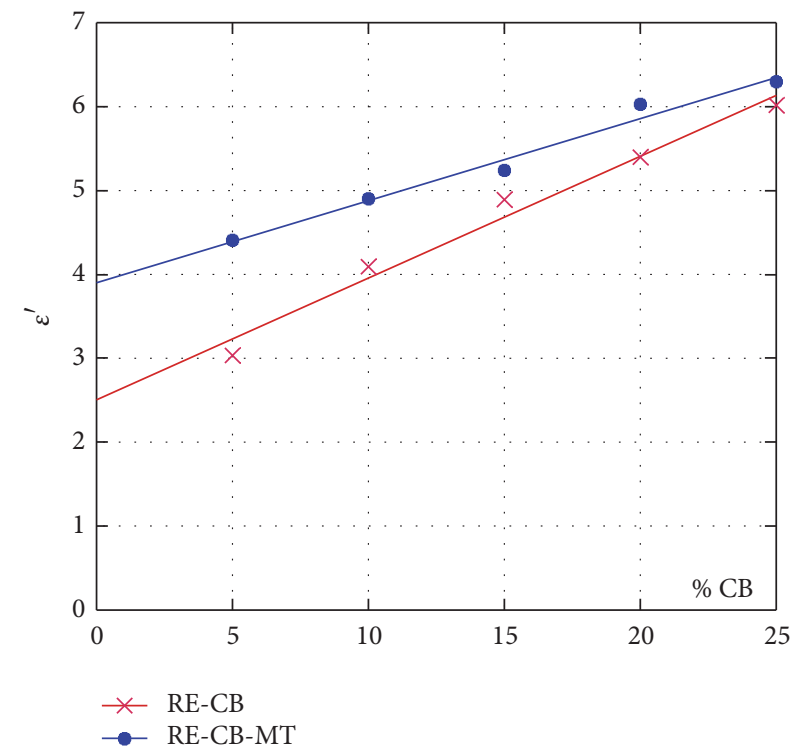

FIGURE 13: Variation of the permittivity $\left(\varepsilon^{\prime}\right)$ for binary (RE-CB) and ternary (RE-CB-MT) composites.

inclusions in the mixture that becomes more important. In this case, the minimal value of the conductivity is of $5.84 *$ $10^{-3}(\Omega \mathrm{m})^{-1}$ for the composites with the composition of (70.2.5). The maximal value of conductivity of this mixture is $16.68 * 10^{-3}(\Omega \mathrm{m})^{-1}$.

\section{The Influence of Magnesium Titanate (MT) on the Carbon Black (CB)}

To determine the influence of (MT) and (CB) on the dielectric behavior of different composites, we undertake a comparative study of dielectric properties between the composites (RE$\mathrm{CB}$ ) and (RE-CB-MT) previously mentioned. In Figure 13, 


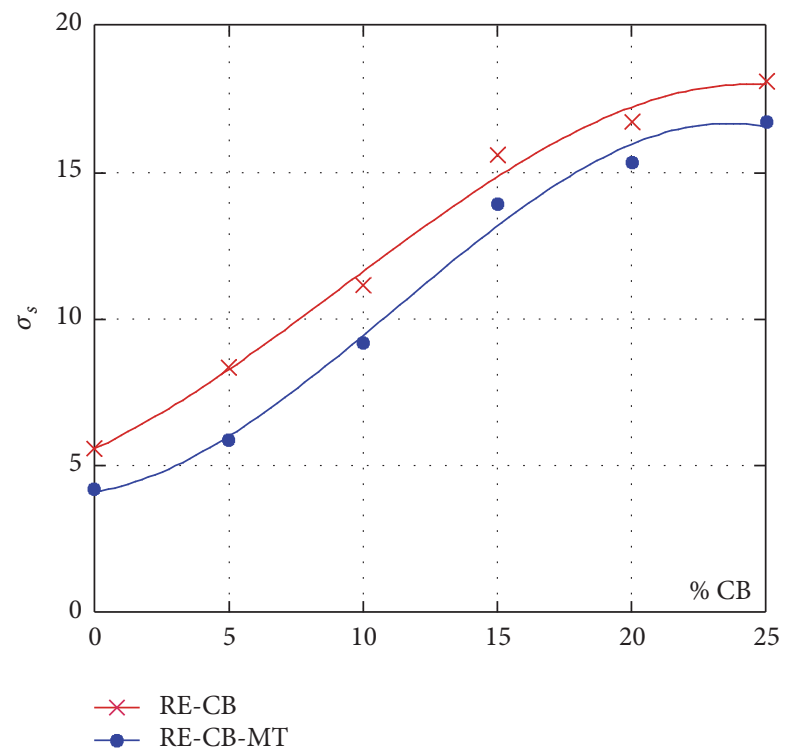

FIGURE 14: Variation of the static conductivity $\left(\sigma_{s} * 10^{-3}(\Omega \mathrm{m})^{-1}\right)$ for binary (RE-CB) and ternary (RE-CB-MT) composites.

the variations of the real parts of the dielectric permittivity $\left(\varepsilon^{\prime}\right)$ are represented for the two types of composites.

The presence of CB inclusion has allowed us to improve the dielectrics properties of composites. The MT inclusion has improved substantially the static dielectric permittivity $\left(\varepsilon^{\prime}\right)$ for high concentrations. Only, the gradual inclusion of MT has driven to a weak growth of $\left(\varepsilon^{\prime}\right)$ for a ternary composite, thus approaching to the same dielectric behavior as for a binary composite (RE-CB). The permittivity values of ternary mixture are more important than the binary one; this is due to the presence of inclusion of MT. The addiction of MT has allowed the augmentation of dielectric constant values in the composites.

However a renewal in conductivity is observed in Figure 14 which is illustrated by the growth of this parameter with the same quantity for all MT concentrations in the ternary composites. Moreover, the same relaxation phenomenon is observed for the two composites and it is characterized by the change of the curve concavity.

For these two types of composites, the binaries composites (RE-CB) conductivity measured values are found to be more important than those obtained for ternary composites (RE-CB-MT). The addiction of MT has contributed to reducing the conductivity for the last composite.

\section{Conclusion}

In this article, we presented a dielectric characterization using the bench of the time domain spectroscopy on binary (RE-CB) and ternary (RE-CB-MT) mixtures. The obtained results show that the evolution of dielectric permittivity is done by phase's nature of composites and shows in some cases a change of attitude around a certain load volume fraction. We can note that from the knowledge of dielectric characterization it can be possible to predict the dielectric behavior of composite material from a simple logarithmic law of Lichtenecker and to verify it from the use of the Bottreau law. This is allowed us to intervene on volume fractions rates of constituents of mixture in order to generate predetermined dielectrics characteristics materials. The addiction of MT has conducted to reducing the conductivity for binary composites (RE-CB). The improvement of the conductivity is an important phenomenon for the hyperfrequency applications, and the effect of the CB on MT increases the conductivity of the ternary composite.

\section{Competing Interests}

The authors declare that they have no competing interests.

\section{References}

[1] A.-M. Bottreau, N. Bouzit, and A. Merzouki, "Dielectric behavior study of some composites polyester/MTiO3 by time domain spectroscopy," EPJ Applied Physics, vol. 18, no. 1, pp. 17-24, 2002.

[2] J. C. Martin, J. M. Fornies-Marquina, and A. M. Bottreau, "Application of permittivity mixture laws to carbon black dielectric characterization by time domain reflectometry," Molecular Physics, vol. 101, no. 12, pp. 1789-1793, 2003.

[3] A. M. Bottreau, "Dielectric study of some composites polymer/carbon in a broadband of frequencies. Part II: modelisation," Journal de Chimie Physique, vol. 94, no. 9, pp. 1587-1601, 1997.

[4] A. M. Bottreau, A. Boutaudon, Az. Merzouki, and Ah. Merzouki, "Dielectric study of some composites polymer carbon in a broad-band offrequencies .1. Experimental results," Journal de Chimie Physique et de Physico-Chimie Biologique, vol. 94, no. 4, pp. 1568-1586, 1997.

[5] K. Lichtenecker and K. Rother, "Die herleitung des logarithmischen mischungsgesetzes als allegemeinen prinzipien der staionaren stromung," Physikalische Zeitschrift, vol. 32, pp. 255-260, 1931.

[6] A.-M. Bottreau, "Modelisation of dielectric behavior of heterogeneous media in correlation with various laws," Journal de Chimie Physique et de Physico-Chimie Biologique, vol. 95, no. 3, pp. 617-641, 1998.

[7] J. C. Martín, "Analysis of the complex effective permittivity of a heterogeneous sample by the finite-difference time-domain method," Canadian Journal of Physics, vol. 87, no. 4, pp. 337-343, 2009.

[8] J. M. Forniés-Marquina and G. Vigo, "Dispositif expérimental pour la mesure des permittivités diélectriques en bande $\mathrm{X}$ et $\mathrm{V}$ H F," Revistas de la Real Academia de Ciencias de Zaragoza, vol. 32, no. 1-2, 1977.

[9] A. Benhamouda, J. M. Forniés-Marquina, N. Bouzit, and N. Bourouba, "Dielectric behavior of ternary composites of epoxy/BaTiO3/(CuO or MgO)," The European Physical Journal Applied Physics, vol. 46, no. 2, Article ID 20404, 2009.

[10] N. Bouzit, J. M. Forniés-Marquina, A. Benhamouda, and N. Bourouba, "Modelling and dielectric behavior of ternary composites of epoxy $\left(\mathrm{BaTiO}_{3} / \mathrm{CaTiO}_{3}\right)$," EPJ Applied Physics, vol. 38, no. 2, pp. 147-152, 2007.

[11] N. Bourouba, K. Lalla, J. P. Martinez Jimenez, and N. Bouzit, "Dielectric behavior of ternary mixtures: epoxy resin plus titanates $(\mathrm{MgTiO} 3, \mathrm{CaTiO} 3$ or BaTiO3) associated to oxides ( $\mathrm{CaO}, \mathrm{MnO} 2$ or $\mathrm{ZnO}), "$ The European Physical Journal Applied Physics, vol. 65, no. 1, Article ID 10202, 2013. 
[12] N. Bouzit, Caractérisation diélectrique de matériaux hétérogènes par spectroscopie temporelle: application à l'étude de composites polyesters chargés par des titanates [Thèse de Doctorat d'Etat], Université Ferhat Abbas Sétif 1, Sétif, Algeria, 2002.

[13] K. Lalla, Caractérisation électromagnétique $(\varepsilon, \sigma, \mu)$ et élaboration des matériaux composites: application à la miniaturisation des composants électroniques [Thèse de Doctorat], Université Ferhat Abbas Sétif 1, Sétif, Algeria, 2015.

[14] A. Bounar and N. Bouzit, "Caractérisation électromagnétique des matériaux composites ( $\mathrm{Re}-\mathrm{MgTiO} 3-\mathrm{NC})(\varepsilon, \sigma)$ par spectroscopie temporelle," in Proceedings of the National Séminaire on Électronics C7COM, Bordj Bou Arreridj, Algeria, 2014, http://fst.univ-bba.dz/.

[15] A. Bounar and N. Bouzit, "Caractérisation diélectrique des matériaux composites Re-MgTiO3-NC," in Proceedings of the 1st National Conference on Electronics and New Technologies (NCENT '15), M'sila, Algeria, May 2015. 

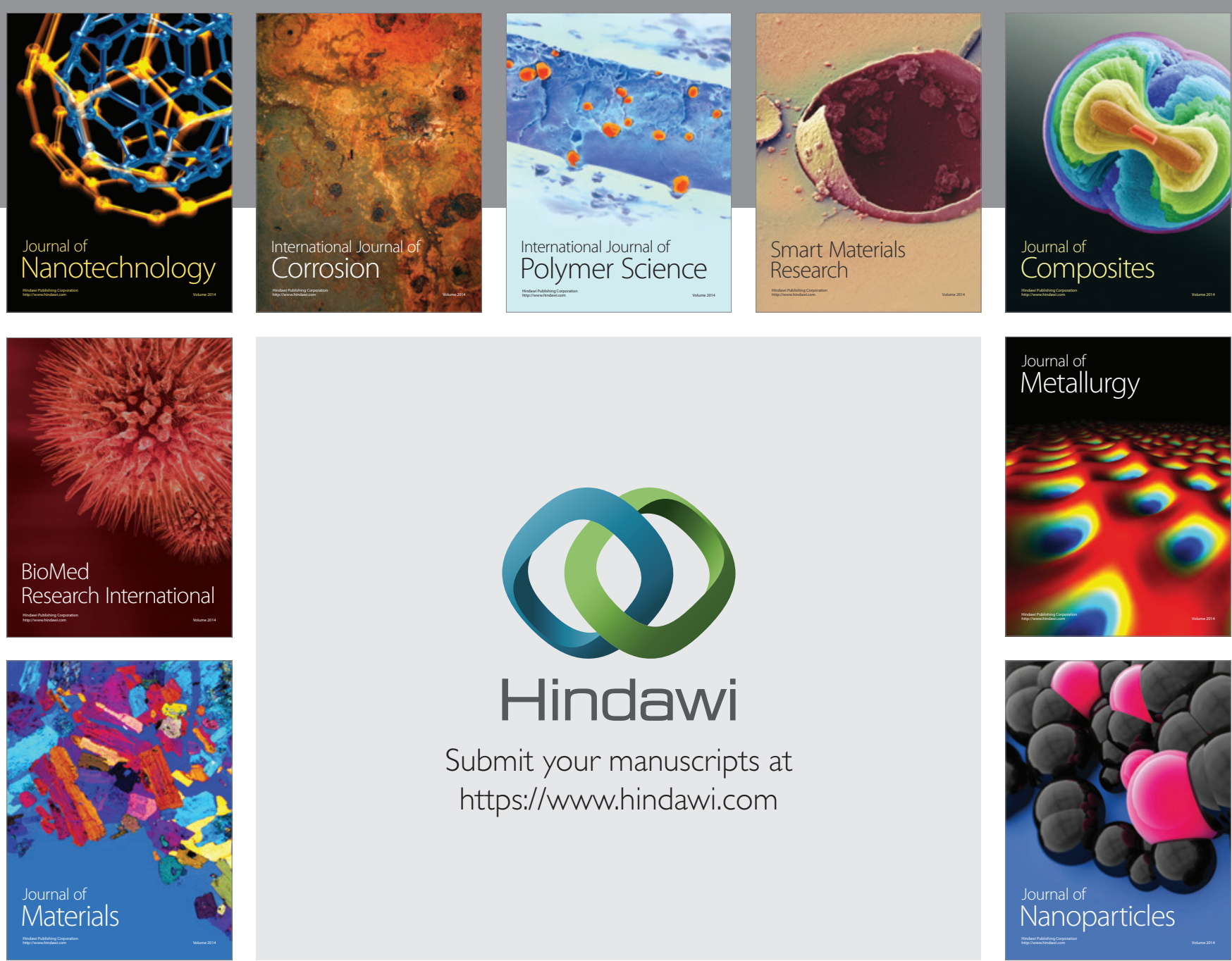

\section{Hindawi}

Submit your manuscripts at

https://www.hindawi.com

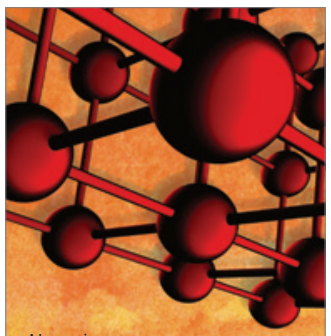

Materials Science and Engineering
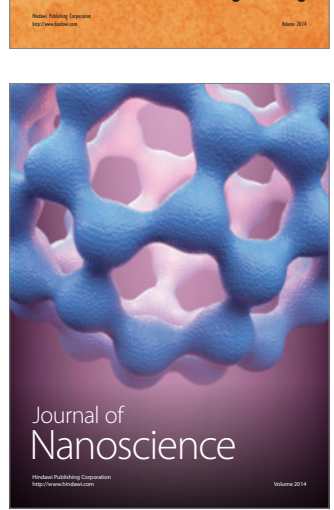
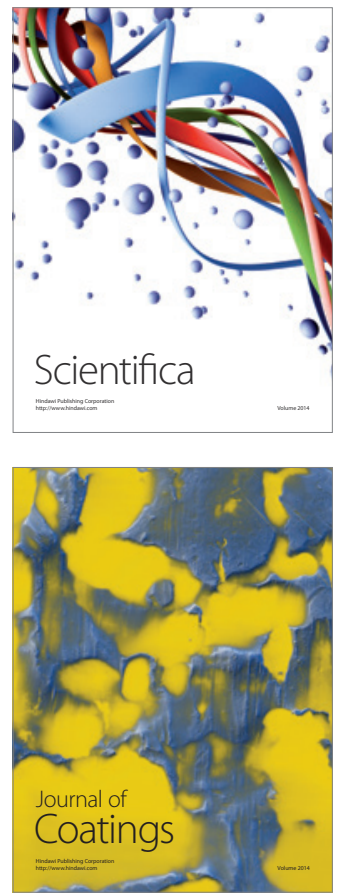
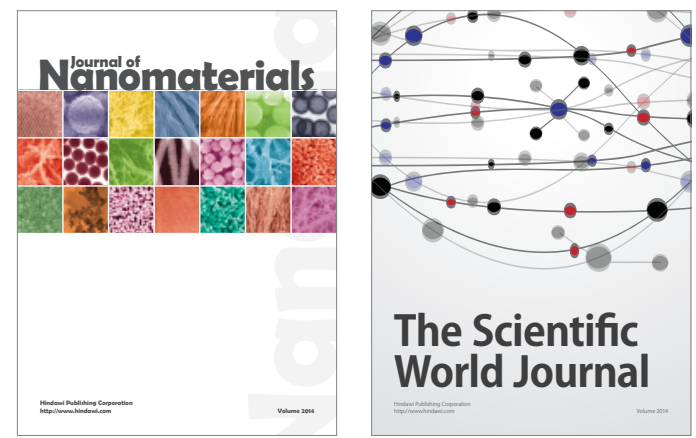

The Scientific World Journal
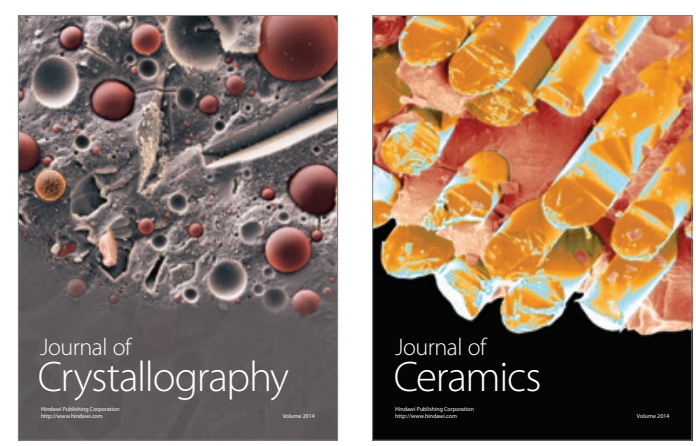
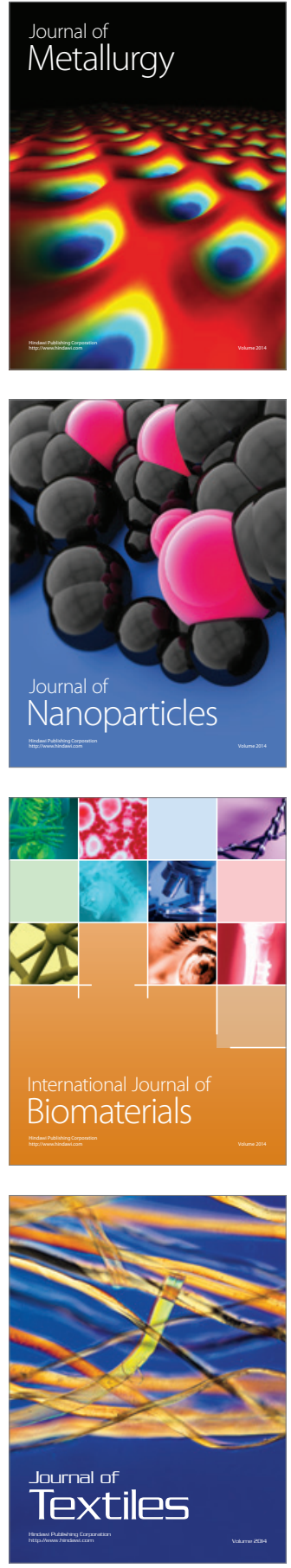